\title{
Anti-aging potential of fish collagen hydrolysates subjected to simulated gastrointestinal digestion and Caco- 2 cell permeation
}

\author{
Hyun Jeong Je ${ }^{1}$ Yoo Kyung Han ${ }^{1} \cdot$ Hyeon Gyu Lee ${ }^{1} \cdot$ In Young Bae ${ }^{2}$ iD
}

Received: 2 January 2019 / Accepted: 25 February 2019 / Published Online: 31 March 2019

(C) The Korean Society for Applied Biological Chemistry 2019

\begin{abstract}
The objectives of this study were to evaluate the antiaging effects and investigate the effect of simulated gastrointestinal (GI) digestion on the anti-aging properties and intestinal permeation of the potential fish collagen hydrolysates (FCH). Therefore, procollagen synthesis, matrix metalloproteinase-1 (MMP-1) production, and Caco-2 cell permeability were analyzed before and after in vitro digestion for $\mathrm{FCHs,} \mathrm{low-molecular} \mathrm{weight}$ fractions $(<1 \mathrm{kDa})$, and high molecular weight fractions $(>1 \mathrm{kDa})$. After being subjected to GI digestion, the level of MMP-1 inhibition was maintained, although the procollagen production was significantly $(>20 \%)$ lower with all samples. Also, the digested FCHs and their $<1 \mathrm{kDa}$ fraction yielded 9.1 and $13.8 \%$ increased peptide transport, respectively, compared to undigested samples. Based on the effective intestinal permeation and high digestive enzyme stability, the $<1 \mathrm{kDa}$ fraction of $\mathrm{FCHs}$ is a potential bioactive material suitable for anti-aging applications in the food and cosmetics industries.
\end{abstract}

Keywords Anti-aging peptide $\cdot$ Cellular permeability $\cdot$ Collagen synthesis Fish collagen hydrolysate $\cdot$ Matrix metalloproteinase-1 inhibition

In Young Bae $(\bowtie)$

E-mail: iybae@kdu.ac.kr

Hyeon Gyu Lee $(\triangle)$

E-mail: hyeonlee@hanyang.ac.kr

${ }^{1}$ Department of Food and Nutrition, Hanyang University, 222, Wangsimniro, Seoungdong-gu, Seoul 04763, Republic of Korea

${ }^{2}$ Department of Food and Nutrition, Far East University, 76-32, Daehak-gil, Gamgok, Eumseong, Chungbuk 27601, Republic of Korea

This is an Open Access article distributed under the terms of the Creative Commons Attribution Non-Commercial License (http://creativecommons. org/licenses/by-nc/3.0/) which permits unrestricted non-commercial use, distribution, and reproduction in any medium, provided the original work is properly cited.

\section{Introduction}

The skin is the largest organ of the human body and consists of the epidermis and the dermis. The epidermis, which is composed of keratinocytes, is the outermost layer of the skin and serves as a boundary between the environment and the body [1]. The underlying dermis layer is mainly comprised of collagen and elastin [2], which are produced by fibroblasts. Approximately $75 \%$ of the dermis is formed of collagen [3], which maintains the structure of the dermis layer.

Skin aging occurs when dermal collagen is degraded, resulting in loss of skin tensile strength and stability [4]. Skin aging can be classified into two types with different causes: intrinsic aging, which occurs inevitably over time, and extrinsic aging, which is caused by ultraviolet (UV) radiation, air pollution, smoking, and poor nutrition [1]. These factors impair skin metabolism, resulting in degradation of the collagenous matrix through the actions of cell surface receptors, protein kinase signal transduction pathways, transcription factors, and enzymes [5].

The collagenase production and collagen synthesis pathways are two major pathways in skin metabolism that are related to collagen degradation. For example, skin aging factors can upregulate the expression of activator protein-1 [6], a transcription factor that is related to the production of matrix metalloproteinases (MMPs). MMPs are enzymes that regulate collagen breakdown, which results in skin degradation. Second, extrinsic factors such as UV radiation can inhibit the expression of transforming growth factor$\beta$ (TGF- $\beta$ ), a cytokine that regulates collagen synthesis by dermal fibroblasts [7]. Reduced levels of TGF- $\beta$ decrease collagen production, leading to imperfect skin repair. Therefore, regulating the collagen and MMP-1 production pathways could potentially prevent skin aging.

Collagen is a molecule with demonstrated anti-aging potential that is currently used in diverse fields such as the food, cosmetics, and biomedical industries. Collagen is the most abundant protein in vertebrates and comprises approximately $30 \%$ of the total protein in the human body [8]. Collagen molecules are composed 
of three $\alpha$-chains that form a linked collagen triple helix; these $\alpha$ chains harbor Gly-X-Y repeat sequences [9]. Collagen is typically rich in proline and hydroxyproline, but factors such as source and animal age can influence the variety of amino acids found in collagen [10].

Recent studies have shown that collagen hydrolysates and peptides derived from collagen exhibit a variety of anti-aging properties. For instance, rats and mice that were fed collagen hydrolysates derived from bovine hide [4], jellyfish [11], and fish scales [8] exhibited increased collagen production and significantly decreased MMP expression. Also, collagen hydrolysates from Chum Salmon skin were found to stimulate collagen synthesis and decrease collagen degradation in a dose-dependent manner [7]. Moreover, Gly-X-Y tripeptides derived from collagen hydrolysates also showed anti-aging properties such as increased skin moisture content, increased skin elasticity, and decreased MMP activities in UV-irradiated hairless mice [12].

Although many studies have illustrated the skin-protecting effects of collagen hydrolysates, very few bioactive peptides have been identified, and the molecular mechanisms by which they exert their anti-aging effects remain unknown. Moreover, collagen hydrolysates from different species, habitats, and tissues each have unique amino acid compositions, which can affect their antiaging properties [13]. Also, the effects of in vitro digestion on the anti-aging properties and the intestinal transport efficacy of collagen hydrolysates have been rarely studied, even though these effects are important factors for applications of collagen hydrolysates in the food, pharmaceutical, and cosmetics industries.

Therefore, the aim of this study was to evaluate the anti-aging effects of potential fish collagen hydrolysates (FCHs) and investigate the effects of in vitro simulated gastrointestinal (GI) digestion on the anti-aging properties and intestinal permeation of the FCHs. For this purpose, different molecular weight fractions were collected, and the anti-aging properties and intestinal transport abilities were characterized before and after in vitro digestion. Specifically, procollagen synthesis, MMP-1 production, and Caco-2 cell permeability were analyzed.

\section{Materials and Methods}

\section{Materials and reagents}

FCHs, produced from tilapia scales and hydrolyzed with a neutral protease (Bacillus amyloliquefaciens), were provided from Nongshim Co., Ltd, Seoul, Korea. The average molecular weight of FCH was approximately $2 \mathrm{kDa}$, and the amino acid composition of FCH is shown in Table 1. Pepsin, pancreatin, 3-(4,5-dimethylthiazol2-yl)-2,5-diphenyltetrazolium bromide (MTT), formic acid, rat tail collagen, and retinoic acid (RA) were purchased from SigmaAldrich Chemical Co. Ltd. (St. Louis, MO, USA). TGF- $\beta_{1}$ was purchased from PeproTech, Inc. (Rocky Hill, NJ, USA). Phosphatebuffered saline (PBS) and penicillin-streptomycin were purchased from Lonza (Walkersville, MD, USA). Dulbecco's modified Eagle medium (DMEM), Hanks' balanced salt solution (HBSS), fetal bovine serum (FBS), $0.25 \%$ trypsin-EDTA, HEPES, glucose solution, and non-essential amino acids (NEAAs) were purchased from Gibco Life Technologies (Grand Island, NY, USA). Hs68 and Caco- 2 cells were obtained from the American Type Culture Collection (Manassas, VA, USA).

\section{Ultrafiltration}

FCHs were fractionated by ultrafiltration (UF) using an Amicon model 8400 UF unit (Millipore Corp., Billerica, MA). The unit contained a Millipore membrane with a molecular mass cutoff of $1 \mathrm{kDa}$. The peptides that permeated the $1 \mathrm{kDa}$ membrane $(<1$ $\mathrm{kDa}$ ) and the peptides that were retained without passing through the $1 \mathrm{kDa}$ membrane $(>1 \mathrm{kDa})$ were both collected. All fractions were lyophilized and stored at $-20{ }^{\circ} \mathrm{C}$.

\section{Simulated gastrointestinal (GI) digestion}

In vitro GI digestion of FCHs and UF fractions was performed using the method of Samaranayaka et al. [14] with slight modifications. Briefly, the digested samples were prepared by dissolving $100 \mathrm{mg}$ of FCHs, their $<1 \mathrm{kDa}$ fraction, and their $>1 \mathrm{kDa}$ fraction separately in $10 \mathrm{~mL}$ of distilled water each. The $\mathrm{pH}$ of each solution was adjusted to 2.0 with $5 \mathrm{~N} \mathrm{HCl}$. Pepsin from porcine gastric mucosa (enzyme to substrate ratio, 1:35 w/w) was added, and the mixture was placed in a shaking incubator for $1 \mathrm{~h}$ at $37^{\circ} \mathrm{C}$. The $\mathrm{pH}$ was then adjusted to 5.3 with $0.9 \mathrm{M} \mathrm{NaHCO}_{3}$ and further adjusted to $\mathrm{pH} 7.5$ with $5 \mathrm{~N} \mathrm{NaOH}$. Porcine pancreas pancreatin (enzyme to substrate ratio, 1:25 w/w) was added to the mixture, which was incubated again with shaking for $2 \mathrm{~h}$ at $37^{\circ} \mathrm{C}$, before being submerged in boiling water for $10 \mathrm{~min}$ to terminate the digestion. Aliquots of the digested sample were cooled at room temperature and stored at $-20{ }^{\circ} \mathrm{C}$ until use.

\section{Cell culture}

Hs68 and Caco-2 cells were both grown in DMEM. The growth medium for Hs68 cells was supplemented with 10\% FBS and 5\% penicillin-streptomycin, whereas the growth medium for Caco-2 cells was supplemented with 10\% FBS, 5\% NEAA, and 5\% penicillin-streptomycin. The cells were maintained at $37{ }^{\circ} \mathrm{C}$ with $5 \% \mathrm{CO}_{2}$ and $95 \%$ humidity. The medium was changed every 2 days. All Hs68 and Caco-2 cells used in this study were between passages 23 and 30 .

\section{Cell viability}

The cytotoxicity of the FCHs was measured using the MTT assay, which is based on the reduction of MTT to purple formazan crystals by mitochondrial dehydrogenases in live cells [15]. Briefly, Caco-2 and Hs68 cells were seeded at a density of $1 \times 10^{4}$ cells/well in a 96-well plate. After 24 hours of incubation, the wells were treated with $20 \mathrm{uL}$ of FCHs and then incubated for an additional 24 hours. Following this incubation, $20 \mu \mathrm{L}$ of $0.5 \mathrm{mg}$ / 
$\mathrm{mL}$ MTT in PBS was added to each well. After 4 hours of incubation, the plate was centrifuged at 1,500 rpm for 5 minutes, and the supernatant was aspirated. Next, $150 \mu \mathrm{L}$ of dimethyl sulfoxide was added to each well to dissolve the formazan crystals, and the amount of formazan was measured using a microplate reader at $540 \mathrm{~nm}$.

\section{Procollagen synthesis assay}

Hs68 cells were seeded in 48 -well plates $\left(5 \times 10^{4}\right.$ cells/well $)$ and cultured at $37{ }^{\circ} \mathrm{C}$ in $5 \% \mathrm{CO}_{2}$. After 24 hours of incubation, the supernatant of each well was aspirated, and the cells were washed with PBS. The FCHs, their $<1 \mathrm{kDa}$ fraction, their $>1 \mathrm{kDa}$ fraction, and the digested samples were each dissolved in serum-free DMEM, after which the cells were treated with samples at concentrations ranging from $0-1,000 \mu \mathrm{g} / \mathrm{mL}$. The cells were incubated for an additional 24 hours, after which the supernatant was collected from each well. The amount of procollagen was measured with a procollagen type I C-peptide assay kit (Takara Bio, Japan).

\section{UV-induced collagenase inhibition assay}

Hs68 cells were seeded in 48 -well plates $\left(5 \times 10^{4}\right.$ cells/well $)$ and cultured at $37{ }^{\circ} \mathrm{C}$ in $5 \% \mathrm{CO}_{2}$. After 24 hours of incubation, the supernatant of each well was aspirated, and the cells were washed with PBS. The FCHs, their $<1 \mathrm{kDa}$ fraction, their $>1 \mathrm{kDa}$ fraction, and the digested samples were each dissolved in serum-free DMEM, after which the cells were treated with samples at concentrations ranging from $0-1,000 \mu \mathrm{g} / \mathrm{mL}$. After an additional 6 hours of incubation, the cells were washed twice with PBS. Under a thin layer of PBS $(100 \mu \mathrm{L} /$ well), the cells were irradiated with $10 \mathrm{~J} / \mathrm{cm}^{2}$ UVA using a UVT UV lamp (Dongseo Science Co., Ltd., Korea). UV strength was measured using a Lutron UV meter (model UV-340A). Immediately after irradiation, the PBS was aspirated, and serum-free medium was added to each well. The cells were incubated for an additional 24 hours, after which the supernatant was collected from each well. The amount of collagenase was measured with a MMP-1 Human Biotrak ELISA kit (Amersham Life Science, USA).

\section{Caco-2 cell permeability assay}

Permeability assays were carried out using cell monolayers grown in 24-well polycarbonate membrane transwell plates. Caco-2 cultures were seeded at a density of $1.5 \times 10^{5}$ cells $/ \mathrm{cm}^{2}$ into each well insert and grown for 10-12 days. Transepithelial electrical resistance (TEER) measurements were conducted to monitor the cell monolayer growth, and cultures with a resistance greater than $300 \Omega \mathrm{cm}^{2}$ were used in the assay. The transport assay was conducted in triplicate.

After removing the growth medium in the apical chambers and basolateral chambers of each well, the cell monolayers were washed twice with transport medium (HBSS supplemented with $25 \mathrm{mM}$ HEPES and $25 \mathrm{mM}$ glucose). Transport medium was then added to each well, and the cell monolayers were preincubated at $37{ }^{\circ} \mathrm{C}$ for $30 \mathrm{~min}$. After incubation, $0.1 \mathrm{~mL}$ of the FCHs, their $<1$ $\mathrm{kDa}$ fraction, their $>1 \mathrm{kDa}$ fraction, and the digested samples was added to each insert, and $0.6 \mathrm{~mL}$ of transport medium was added to the basolateral chambers. The transwell plates were placed on a rotating shaker (speed, $60 \mathrm{rpm}$ ) throughout the permeability assay. After $2 \mathrm{~h}$, the amounts of peptides transported across the cell monolayers were determined by analyzing aliquots of transport medium taken from each well using a Pierce BCA protein assay kit (Rockford, IL, USA). The efficiency of peptide transport, expressed as percent permeability for each sample, was calculated by the following equation:

\section{Amino acid composition}

Amino acid was analyzed using a Waters HPLC system equipped with a Waters 510 pump and a Waters Pico-Tag column $(3.9 \times 300$ $\mathrm{mm}, 4 \mu \mathrm{m})$. The mobile phases consisted of $140 \mathrm{mM}$ sodium acetate in $6 \%$ acetonitrile (A) and $60 \%$ acetonitrile (B), and the following gradient was used: $86 \%$ A at $9 \mathrm{~min}, 80 \% \mathrm{~A}$ at $9.2 \mathrm{~min}$, $54 \% \mathrm{~A}$ at $17.5 \mathrm{~min}$, and $0 \% \mathrm{~A}$ at $17.7 \mathrm{~min}$. The sample was hydrolyzed with acid and labeled with phenylisothiocyanate. After labeling, $10 \mu \mathrm{L}$ of the sample was injected into the column, and peaks were monitored at $250 \mathrm{~nm}$ by a UV detector.

\section{Statistical analysis}

All data were expressed as the mean \pm standard deviation for three independent samples. Data were evaluated using one-way ANOVA followed by the Duncan's multiple range test and t-tests (SPSS Version 21.0, SPSS Inc., Chicago, IL, USA). P-values under 0.05 were considered statistically significant.

\section{Results and Discussion}

\section{Anti-aging property of fish collagen hydrolysate}

The toxicity of FCHs to Hs68 and Caco-2 cells was investigated using the MTT assay. As shown in Fig. 1A, the viability of Hs68 cells treated with FCHs $(0-1,000 \mu \mathrm{g} / \mathrm{mL})$ was on average $80 \%$ that of nontreated control cells; this observation held for all concentrations. Next, procollagen production and MMP-1 production were analyzed in the presence of FCHs $(0-1,000 \mu \mathrm{g} / \mathrm{mL})$. The toxicity of FCHs to Caco-2 cells at concentrations of $0-5,000 \mu \mathrm{g} /$ $\mathrm{mL}$ was also assessed; results are shown in Figure 1B. Caco-2 cells did not exhibit reduced viability at any concentration; thus, intestinal transport assays were conducted in this FCH concentration range.

The amounts of collagen synthesized after treating Hs68 cells with the FCHs, their $<1 \mathrm{kDa}$ fraction, and their $>1 \mathrm{kDa}$ fraction were determined using a procollagen type I C-peptide ELISA assay. As shown in Fig. 2, all types of samples led to an increase in collagen formation. The collagen-synthesizing effect of fish collagen-derived samples may be due to the amino acid 

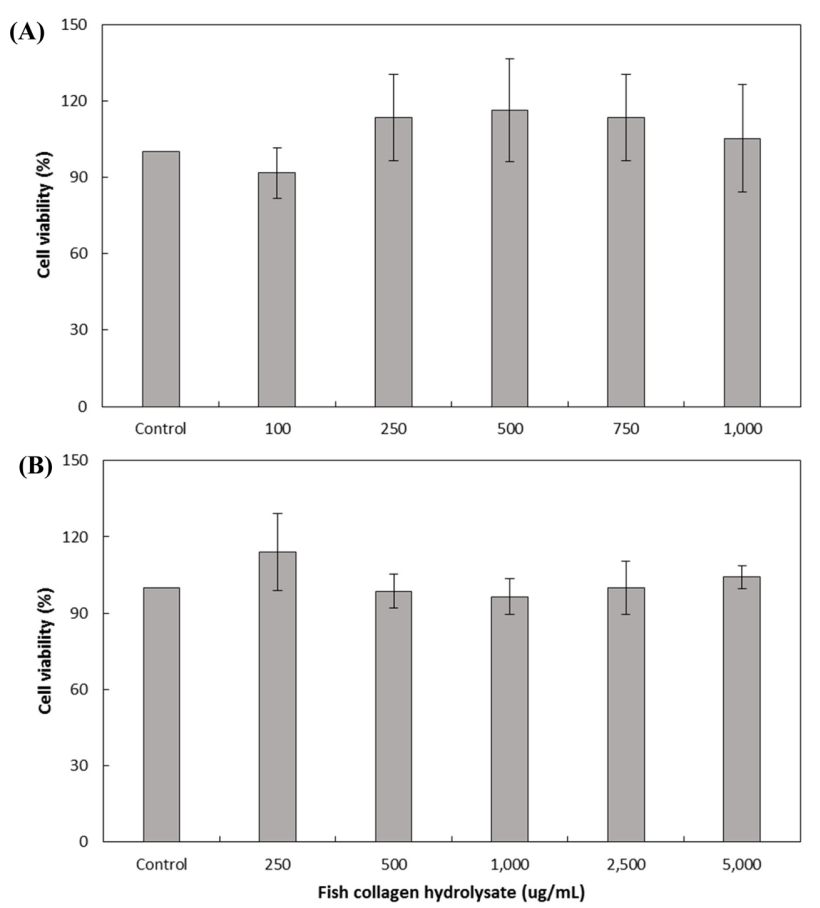

Fig. 1 Viabilities of (A) Hs68 cells and (B) Caco-2 cells treated with fish collagen hydrolysates

Table 1 Amino acid compositions of fish collagen hydrolysates (FCHs) and their $<1 \mathrm{kDa}$ fraction

\begin{tabular}{lcc}
\hline \hline \multirow{2}{*}{\multicolumn{1}{c}{ Amino acid }} & \multicolumn{2}{c}{ Composition $(\mathrm{g} / 100 \mathrm{~g})^{\mathrm{a}}$} \\
\cline { 2 - 3 } & $\mathrm{FCH}$ & $<1 \mathrm{kDa}$ \\
\hline Glycine & 23.60 & 32.44 \\
Alanine & 11.78 & 23.89 \\
Proline & 11.01 & $\mathrm{ND}^{\mathrm{b}}$ \\
Glutamic acid + glutamine & 10.16 & 5.15 \\
Hydroxyproline & 8.92 & 1.16 \\
Arginine & 7.91 & 15.61 \\
Aspartic acid + asparagine & 5.59 & 1.71 \\
Serine & 3.54 & $\mathrm{ND}$ \\
Threonine & 3.28 & 3.53 \\
Lysine & 3.19 & 8.06 \\
Leucine & 2.85 & $\mathrm{ND}$ \\
Valine & 2.36 & $\mathrm{ND}$ \\
Phenylalanine & 1.73 & 1.58 \\
Isoleucine & 1.40 & $\mathrm{ND}$ \\
Histidine & 1.10 & 1.09 \\
\hline
\end{tabular}

${ }^{\mathrm{a}}$ Expressed as grams per $100 \mathrm{~g}$ of amino acids. ${ }^{\mathrm{b}}$ Not detected

composition of FCH (Table 1). The major amino acids in FCH were Gly, Ala, Pro, Glu, Hyp, and Arg; together, these six amino acids comprised approximately $73.4 \%$ of $\mathrm{FCH}$. On the other hand, the $<1 \mathrm{kDa}$ fraction was mainly composed of Gly, Ala, and Arg comprised approximately $72.9 \%$. Ala, which is one of the most abundant amino acid in FCH and the $<1 \mathrm{kDa}$ fraction, has been reported to contribute to collagen formation [16]. Arg is a precursor of proline synthesis [17], which is an important amino

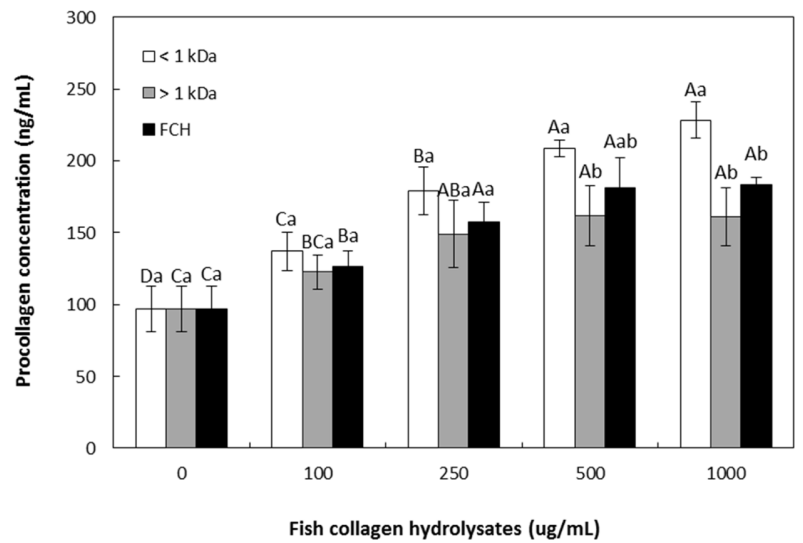

Fig. 2 Quantitation of procollagen synthesis by Hs68 cells treated with fish collagen hydrolysates (FCHs), their $<1 \mathrm{kDa}$ fraction, and their $>1$ $\mathrm{kDa}$ fraction for $24 \mathrm{~h}$. Means with capital letters of the same sample and small letters of the same concentration are significantly different $(p$ $<0.05)$

acid in collagen synthesis. Furthermore, a variety of collagenderived peptides composed of diverse combinations of amino acids have been reported to have collagen synthesizing and MMP1 inhibiting effects. A research study reported that Chum salmon skin hydrolysate consisting of Gly, Glu, Pro, and Hyp significantly increased collagen production and inhibited MMP-1 expression [7]. Additionally, collagen hydrolysate from bovine hide with high contents of Gly, Glu, Arg, Pro, and Hyp showed increased collagen synthesis and decreased MMP-2 production [18]. Jellyfish collagen hydrolysate rich with Gly, Pro, Glu, Asp, and Ala was reported to show collagen synthesis and antioxidant activity [11]. Another study revealed that specific ratios of Arg, Glu, Val, Ile, and Leu could synthesize collagen and inhibit skin aging [19]. These studies show that there can be numerous combinations of amino acid compositions that could contribute to skin protective effects. Nonetheless, Gly, Ala, and Arg are considered to be the major amino acids found in most of the previous literatures.

Among the samples, the $<1 \mathrm{kDa}$ fraction significantly increased the expression of type I collagen at all tested concentrations (100, 250,500 , and $1,000 \mu \mathrm{g} / \mathrm{mL} ; 137.01,179.18,208.76$, and 228.4 $\mathrm{ng} / \mathrm{mL}$, respectively) compared with the control group (97.02 ng/ $\mathrm{mL}$ ). The amount of collagen released into the medium increased in a concentration-dependent manner for the $<1 \mathrm{kDa}$ fraction, whereas the FCHs and $>1 \mathrm{kDa}$ fraction did not exhibit this dosedependent increase. Also, the amounts of collagen produced after treatment with the FCHs, their $<1 \mathrm{kDa}$ fraction, and their $>1 \mathrm{kDa}$ fraction were significantly different for treatments at 500 and $1,000 \mu \mathrm{g} / \mathrm{mL}$. Therefore, the $<1 \mathrm{kDa}$ fraction was determined to be the most effective in producing collagen in Hs68 cells and thus to have the greatest potential for improving skin quality.

The effects of UV radiation on MMP-1 production after treating Hs68 cells with the FCHs, their $<1 \mathrm{kDa}$ fraction, and their $>1 \mathrm{kDa}$ fraction are shown in Fig. 3. The level of extracellular 


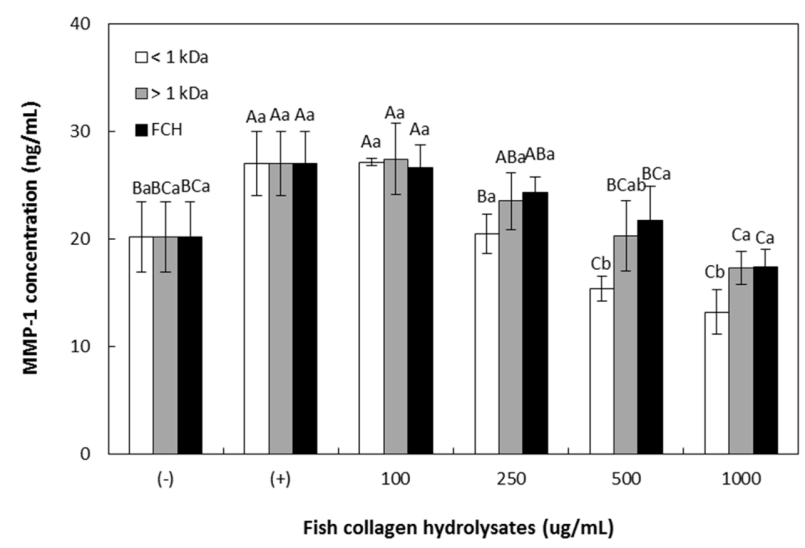

Fig. 3 Quantitation of MMP-1 production by Hs68 cells treated with fish collagen hydrolysates (FCHs), their $<1 \mathrm{kDa}$ fraction, and their $>1 \mathrm{kDa}$ fraction for $24 \mathrm{~h}$ after UVA irradiation $\left(10 \mathrm{~J} / \mathrm{cm}^{2}\right) .(-)$ and $(+)$ designate the two control groups (unexposed and exposed to UVA, respectively). Means with capital letters of the same sample and small letters of the same concentration are significantly different $(p<0.05)$

MMP-1 decreased in a dose-dependent manner for all samples. Several studies concerning peptides with similar amino acid compositions of FCH (Table 1) have been reported to show MMP-1 inhibiting effects. Liang et al. [7] reported that Chum salmon skin hydrolysate consisting of Gly, Glu, Pro, and Hyp significantly inhibited MMP-1 expression, and collagen hydrolysates from bovine hide with high contents of Gly, Glu, Arg, Pro, and Hyp showed decrease in MMP-2 production. Thus, high contents of Glu, Arg, Pro, and Hyp may lead to MMP-1 inhibition.

Furthermore, it could be seen that the $<1 \mathrm{kDa}$ fraction inhibited MMP-1 production most effectively. Treating cells with the $<1$ $\mathrm{kDa}$ fraction $(250-1,000 \mu \mathrm{g} / \mathrm{mL})$ significantly reduced the amount of MMP-1 (20.43, 15.33, and $13.18 \mathrm{ng} / \mathrm{mL})$ compared with the UV-irradiated control group $(26.98 \mathrm{ng} / \mathrm{mL})$. Also, the amounts of collagen produced after treatment with the FCHs, their $<1 \mathrm{kDa}$ fraction, and their $>1 \mathrm{kDa}$ fraction were significantly different when the treatments were used at concentrations between 500 and $1,000 \mu \mathrm{g} / \mathrm{mL}$. Therefore, the $<1 \mathrm{kDa}$ fraction was determined to be the most potent for reducing collagenase expression in Hs68 cells.

Effects of in vitro digestion on the anti-aging property and intestinal permeation of $\mathrm{FCH}$

The effects of in vitro simulated GI digestion on the anti-aging properties of $\mathrm{FCHs}$, their $<1 \mathrm{kDa}$ fraction, and their $>1 \mathrm{kDa}$ fraction in Hs68 cells are shown in Fig. 4. The amounts of procollagen synthesized after treatment with $\mathrm{FCHs}$, their $<1 \mathrm{kDa}$ fraction, and their $>1 \mathrm{kDa}$ fraction were decreased significantly by $23.98,27.16$, and $20.54 \%$, respectively, after GI digestion compared to the same samples before digestion (Fig. 4A). Although the $<1$ $\mathrm{kDa}$ fraction stimulated the highest level of collagen synthesis of all samples regardless of digestion status, the level of degradation
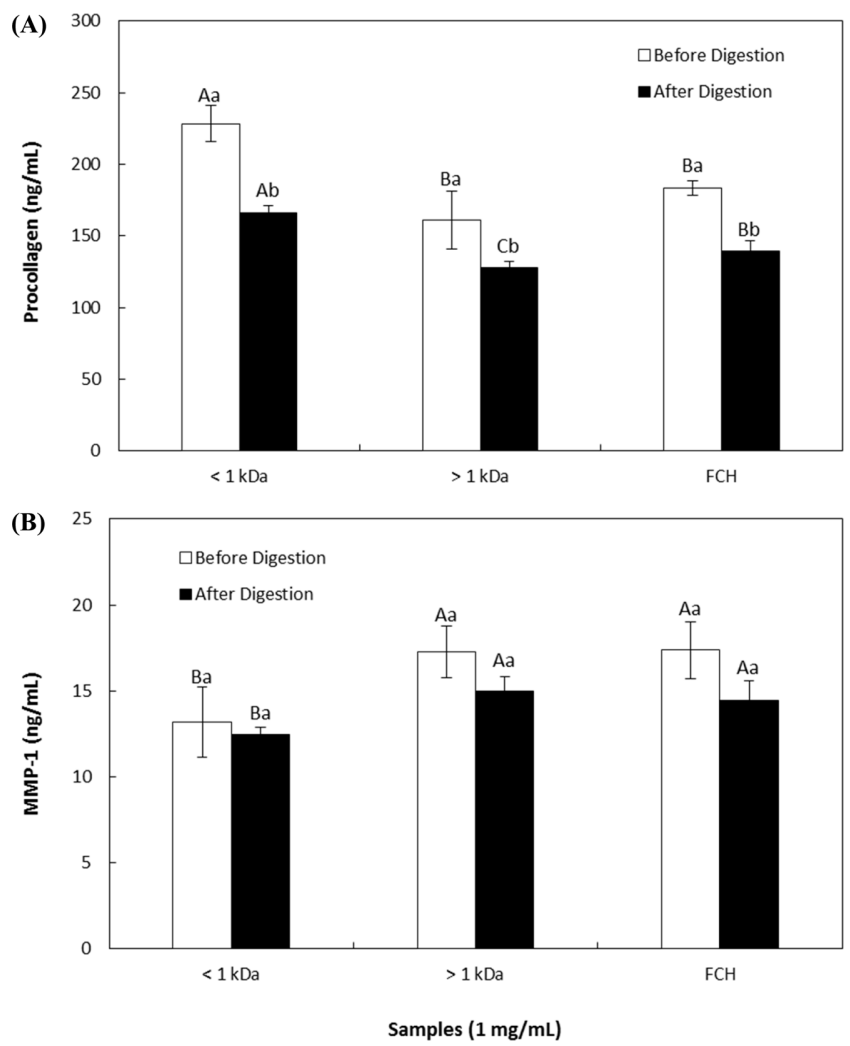

Fig. 4 Comparison of (A) procollagen synthesis and (B) MMP-1 production in Hs68 cells treated with nondigested versus digested fish collagen hydrolysates (FCHs), their $<1 \mathrm{kDa}$ fraction, and their $>1 \mathrm{kDa}$ fraction for $24 \mathrm{hrs}$. Means with capital letters of the same digestion level and small letters of the same sample are significantly different $(p<0.05)$

was also greatest for the $<1 \mathrm{kDa}$ fraction. On the other hand, there was no significant difference in the amounts of MMP-1 produced after stimulation with FCHs, their $<1 \mathrm{kDa}$ fraction, and their $>1$ $\mathrm{kDa}$ fraction before versus after GI digestion (Fig. 4B). The $<1$ $\mathrm{kDa}$ fraction showed the highest collagenase-inhibiting ability of all samples tested.

These results may be attributed to the effects of digestive enzymes that cleave specific sites in peptides. Since pepsin is known to cleave peptide bonds located at the carboxyl side of Phe, Trp, Tyr, and Leu residues [20], theoretically, no peptide bonds were cleaved in the GRRGNK anti-aging peptide. On the other hand, pancreatin is a mixture of various enzymatic proteases, including trypsin. Trypsin cleaves internal bonds at Lys or Arg residues and possesses higher hydrolysis activity due to the activation of other pancreatic proenzymes [21]. Thus, it is possible that GRRGNK was degraded into smaller peptides and amino acids during pancreatin digestion, and that this degradation led to a decrease in procollagen synthesis. Also, the MMP-1 inhibition activity was sustained after GI digestion, which implies that a smaller peptide may be involved in the regulation of MMP-1 activity.

The cellular transport abilities of FCHs and digested FCHs in Caco-2 cell monolayers were next investigated (Table 2). Analysis 
Table 2 Caco-2 cell permeabilities of fish collagen hydrolysates (FCHs), their $<1 \mathrm{kDa}$ fraction, and their $>1 \mathrm{kDa}$ fraction

\begin{tabular}{|c|c|c|}
\hline \multirow{2}{*}{ Samples } & \multicolumn{2}{|c|}{ Gastrointestinal digestion (\%) } \\
\hline & Before & After \\
\hline $\mathrm{FCH}$ & $32.8 \pm 0.8 \mathrm{Bb}$ & $35.8 \pm 0.2 \mathrm{Ba}$ \\
\hline$<1 \mathrm{kDa}$ & $34.0 \pm 0.9 \mathrm{Ab}$ & $38.7 \pm 0.5 \mathrm{Aa}$ \\
\hline$>1 \mathrm{kDa}$ & $32.2 \pm 0.2 \mathrm{Ba}$ & $32.2 \pm 0.5 \mathrm{Ca}$ \\
\hline
\end{tabular}

Means with capital letters of the same column and small letters of the same row are significantly different $(p<0.05)$

of the peptide concentrations in permeates before digestion indicated that $32.8,34.0$, and $32.2 \%$ of the FCHs, their $<1 \mathrm{kDa}$ fraction, and their $>1 \mathrm{kDa}$ fraction, respectively, were transported across the intestinal barrier. The $<1 \mathrm{kDa}$ fraction exhibited significantly higher permeability than the FCHs and the $>1 \mathrm{kDa}$ fraction, indicating that size is an important factor for intestinal peptide transport.

Peptides are primarily transported as dipeptides and tripeptides through the processes of carrier-mediated transport, transcytosis, and paracellular passive diffusion [22]. Although a few reports have concluded that some long-chain polypeptides can be transported by transcytosis, such as the ACE inhibitory peptide VLPVPQK [23], the amount of peptide absorbed via transcytosis is generally regarded to be insignificant [24]. Thus, large peptides are predominantly broken down by proteases generated by endothelial cells [25] for intestinal permeation. Since the $<1 \mathrm{kDa}$ fraction is composed of smaller peptides compared to the FCHs and the $>1 \mathrm{kDa}$ fraction, more peptide bonds would have been cleaved by cellular proteases.

After in vitro GI digestion, the total amounts of peptides transported across the Caco- 2 cell layers for the FCHs, their $<1$ $\mathrm{kDa}$ fraction, and their $>1 \mathrm{kDa}$ fraction were $35.8,38.7$, and $32.2 \%$, respectively. There was a significant difference between the digested samples and a noticeable increase in permeability for FCHs and the $<1 \mathrm{kDa}$ fraction compared to the same samples before digestion. We presume that the breakdown of peptides by pepsin-pancreatin digestion, as previously discussed, led to increased peptide transport of FCHs and the $<1 \mathrm{kDa}$ fraction. On the other hand, the $>1 \mathrm{kDa}$ fraction showed no significant difference in internal transport between samples before versus after digestion, indicating that larger peptides are less susceptible to digestive enzymes compared to peptides with smaller molecular weights.

Thus, the results in this study show that the intestinal peptide transport increased as the molecular weight decreased, and the anti-aging ability was maintained regardless of the enzymatic digestion. As a result, it could be established that the $<1 \mathrm{kDa}$ fraction of FCH is a potential bioactive peptide with effective intestinal permeation and digestive enzyme stability, suitable for the application in anti-aging foods and cosmetic products.

Acknowledgments This work was supported by the Far East University Research Grant (FEU2018S03).

\section{References}

1. Gragnani A, Cornick SM, Chominski V, Ribeiro de Noronha SM, Alves Corrêa de Noronha SA, Ferreira LM (2014) Review of major theories of skin aging. Adv Aging Res 3: 265-284

2. Brohem CA, da Silva Cardeal LB, Tiago M, Soengas MS, de Moraes Barros SB, Maria-Engler SS (2011) Artificial skin in perspective: concepts and applications. Pigm Cell Melanoma R 24: 35-50

3. Michel APM, Liakat S, Bors K, Gmachl CF (2013) In vivo measurement of mid-infrared light scattering from human skin. Biomed Opt Express 4: $520-530$

4. Zague V, de Freitas V, Rosa MdC, de Castro GÁ, Jaeger RG, MachadoSantelli GM (2011) Collagen hydrolysate intake increases skin collagen expression and suppresses matrix metalloproteinase 2 activity. J Med Food 14: 618-624

5. Fisher GJ, Kang S, Varani J, Bata-Csorgo Z, Wan Y, Datta S, Voorhees JJ (2002) Mechanisms of photoaging and chronological skin aging. Arch Dermatol 138: 1462-1470

6. Mukherjee PK, Maity N, Nema NK, Sarkar BK (2011) Bioactive compounds from natural resources against skin aging. Phytomedicine 19: 64-73

7. Liang J, Pei X, Zhang Z, Wang N, Wang J, Li Y (2010) The protective effects of long-term oral administration of marine collagen hydrolysate from chum salmon on collagen matrix homeostasis in the chronological aged skin of Sprague-Dawley male rats. J Food Sci 75: H230-H238

8. Tanaka M, Koyama Y, Nomura Y (2009) Effects of collagen peptide ingestion on UV-B-induced skin damage. Biosci Biotechnol Biochem 73: 930-932

9. Ferreira AM, Gentile P, Chiono V, Ciardelli G (2012) Collagen for bone tissue regeneration. Acta Biomater 8: 3191-3200

10. Gómez-Guillén MC, Giménez B, López-Caballero ME, Montero MP (2011) Functional and bioactive properties of collagen and gelatin from alternative sources: A review. Food Hydrocol 25: 1813-1827

11. Zhuang Y, Hou H, Zhao X, Zhang Z, Li B (2009) Effects of collagen and collagen hydrolysate from jellyfish (Rhopilema esculentum) on mice skin photoaging induced by UV irradiation. J Food Sci H183-H188

12. Pyun HB, Kim M, Park J, Sakai Y, Numata N, Shin JY, Shin HJ, Kim DU, Hwang JK (2012) Effects of collagen tripeptide supplement on photoaging and epidermal skin barrier in UVB-exposed hairless mice. Preven Nutr Food Sci 17: 245-253

13. Wang L, An X, Yang F, Xin Z, Zhao L, Hu Q (2008) Isolation and characterisation of collagens from the skin, scale and bone of deep-sea redfish (Sebastes mentella). Food Chem 108: 616-623

14. Samaranayaka AG, Kitts DD, Li-Chan EC (2010) Antioxidative and angiotensin-I-converting enzyme inhibitory potential of a Pacific Hake (Merluccius productus) fish protein hydrolysate subjected to simulated gastrointestinal digestion and Caco-2 cell permeation. J Agric Food Chem 58: 1535-1542

15. Shi M, Cai Q, Yao L, Mao Y, Ming Y, Ouyang G (2006) Antiproliferation and apoptosis induced by curcumin in human ovarian cancer cells. Cell Biol Intern 30: 221-226

16. Cho S, Koo JR, A JS, Kim SB (2014) Physicochemical properties of gelatin from jellyfish Rhopilema hispidum. Fish Aquat Sci 17: 299-304

17. Mohan S, Wu CC, Shin S, Fung HL (2012) Continuous exposure to larginine induces oxidative stress and physiological tolerance in cultured human endothelial cells. Amino Acids 43: 1179-1188

18. Zague V, Freitas V, Rosa MC, Castro GA, Jaeger RG, Machado-Santelli M (2011) Collagen hydrolysate intake increases skin collagen expression and suppresses matrix metalloproteinase 2 activity. J Med Food 14: 618624

19. Williams JZ, Abumrad N, Barbul A (2002) Effect of a specialized amino acid mixture on human collagen deposition. Annals of surgery 236: 369 375

20. Rajamohamed SH, Aryee ANA, Hucl P, Patterson CA, Boye JI (2013) In 
vitro gastrointestinal digestion of glabrous canaryseed proteins as affected by variety and thermal treatment. Plant Food Hum Nutr 68: 306-312

21. Whitcomb DC, Lowe ME (2007) Human pancreatic digestive enzymes. Digest Dis Sci 52: 1-17

22. Miguel M, Dávalos A, Manso MA, de la Peña G, Lasunción MA, LópezFandiño R (2008) Transepithelial transport across Caco-2 cell monolayers of antihypertensive egg-derived peptides. PepT1-mediated flux of Tyr-
Pro-Ile. Mol Nutr Food Res 52: 1507-1513

23. Vij R, Reddi S, Kapila S, Kapila R (2016) Transepithelial transport of milk derived bioactive peptide VLPVPQK. Food Chem 190: 681-688

24. Wada Y, Lönnerdal B (2014) Bioactive peptides derived from human milk proteins-mechanisms of action. J Nutr Biochem 25: 503-514

25. Morishita M, Peppas NA (2006) Is the oral route possible for peptide and protein drug delivery? Drug Discov Today 11: 905-910 